\title{
Relationship between Bacteria and Ciliate Protozoa in the Sheep Rumen
}

\author{
By Y. KURIHARA*, J. MARGARET EADIE, P. N. HOBSON \\ AND S. O. MANN \\ Rowett Research Institute, Bucksburn, Aberdeen
}

(Accepted for publication 2 October 1967 )

\begin{abstract}
SUMMAR Y
Two sheep were reared together and then kept on a standard diet over a period of 9 months. The rumen of one sheep contained a mixed population of ciliate protozoal species; the other was initially unfaunated, then faunated with Entodinium caudatum and then with Entodinium and Polyplastron multivesiculatum. For each sheep diurnal and day-to-day variations in total concentration, and concentration of particular types, of bacteria, in viable counts of bacteria on non-selective and differential media and in concentrations of the different protozoal species, were determined. Measurements were also made of in vitro rates of fermentation, rumen $\mathrm{pH}$ and ammonia and volatile fatty-acid concentrations. The presence of protozoa decreased rumen bacterial concentrations and increased ammonia and volatile fatty-acid concentrations. However, these changes were not always completely clear-cut since the protozoa changed the patterns of diurnal variation not only of bacterial numbers but of some metabolic activities and metabolites and also altered the balance of bacterial types. These results are discussed in the context of interactions between bacteria and protozoa and between protozoal species. The main effects of faunation of the rumen seem to be caused by non-selective ingestion of small bacteria by the protozoa.
\end{abstract}

\section{INTRODUCTION}

The rumen contents of sheep and other ruminants contain a population of bacteria and protozoa. Whilst the rumen microbial population exists symbiotically with the host animal, there are also symbiotic relationships between the various micro-organisms in that, taken over a (long) period, the micro-organisms form a stable population in which in many cases one organism exists because of its relationship to another, e.g. it may depend on synthesis of growth factors by another organism. The relationship between the larger protozoa, the ciliates, and the bacteria and the relationship between protozoa and the host have been of interest since the protozoa were first observed. The latter relationship is outside the scope of the present work as too few animals were used to make statistically useful observations. However, it may be mentioned that recent work shows that although the overall processes of rumen metabolism are similar in the presence or absence of protozoa, the presence of protozoa may cause some slight improvement in the growth of the animal (Abou Akkada \& El Shazly, 1964). The first relationship has been the subject of some direct and indirect experiments. Indirectly, biochemical tests, principally on washed suspensions of pro-

* Present address: Biological Institute, Tohoku University, Sendai, Japan. 
tozoa, have shown that the protozoa possess hydrolytic and fermentative enzyme systems of their own and do not depend on bacterial enzyme systems for degradation of carbohydrate nutrients, as had been at one time suggested. More directly, observations on suspensions and growing cultures of a number of species of rumen protozoa have shown that they ingest bacteria and the ingested bacteria probably serve as a nitrogen source for the protozoa (see, for instance, Coleman, 1964). These experiments were done in vitro. In vivo observations show that the concentration of bacteria in the rumen contents of a faunated sheep is less than that in an unfaunated sheep, and that inoculation of an unfaunated sheep with ciliate protozoa leads to a rapid decrease in concentration of bacteria as the protozoal population develops (Eadie \& Hobson 1962). In the present work an attempt has been made to analyse the interactions between some protozoal and bacterial populations of the rumen.

\section{METHODS}

Sheep. The animals used (nos. 27, 28) were two Cheviot females from a set of triplets. The general basis of rearing ciliate-free sheep has been described by Eadie ( $1962 a$ ), and the animals were bottle-fed cows' milk, given dried grass (ad lib.) from 4 weeks old and weaned at 13 weeks. They were then fed a concentrate mixture (roo g.; 4 parts ground maize, I crushed oats, I wheat bran, $\frac{1}{2}$ linseed cake meal, $\frac{1}{2}$ white fish meal) three times a day, with dried grass ad lib. for 4 months, and then were given $300 \mathrm{~g}$. dried grass and $\mathrm{I} 50 \mathrm{~g}$. concentrates fed at $8 \mathrm{a} . \mathrm{m}$. and $4 \mathrm{p} . \mathrm{m}$. This was varied slightly in quantity but not in proportions ( 2 dried grass: I concentrates) over the next 2 months and then throughout the experimental period (from about 9 to 18 months old) the feed was standardized at $210 \mathrm{~g}$. dried grass $+\mathrm{I} 40 \mathrm{~g}$. concentrates ( 3 dried grass: 2 concentrates) fed at 8 a.m. and 4-4.30 p.m. The feed was generally consumed within I hr, and water, though available during the day, was also taken mainly at this time. The animals were fitted with rumen cannulae at 7 months old. They were kept in the same pen for the first 12 weeks, when the rumen of 27 was inoculated with mixed protozoa (Eadie, 1962a). The inoculation was repeated at 13 weeks, after which all species in the inoculum became established. After this the sheep were kept separated, but still in the same room as other faunated and unfaunated animals so that they had equal opportunities for airborne inoculation with the normal rumen bacteria and flagellate protozoa. Sheep 28 did not at times eat all of its feed, but these periods of greatly decreased intake did not coincide with any of the observations described.

Protozoal populations. The inoculum of mixed protozoa was a suspension concentrated from sheep rumen contents and contained bacteria (Eadie, I $962 a$ ). Sheep 27 was inoculated with a mixture of Isotricha prostoma, I. intestinalis, Dasytricha ruminantium, Polyplastron multivesiculatum, Ophryoscolex tricoronatus, Diploplastron affine and various Entodinium species including $E$. caudatum and the large E. bursa Stein. Sheep 28 was inoculated at 12 months old with Entodinium caudatum and at 14 months old with Polyplastron multivesiculatum. These ciliates were obtained from isolated sheep containing limited protozoal populations. The same populations had been used previously for bacterial experiments (Abou Akkada \& Howard, I960; Abou Akkada, Eadie \& Howard, 1963). The inocula (introduced through the rumen cannula) were approximately I000 ciliates contained in I $\mathrm{ml}$. of a well-washed, buffered suspension in which only a few bacteria adherent to the protozoa were present. Only E. caudatum 
was present in the first sheep population, but after the second inoculation some other small Entodinia, which were present in the inoculum, developed along with P. multivesiculatum.

Sampling procedures. Samples were obtained via the rumen cannula by gentle suction through a wide-bore glass tube from the same position in the rumen each time.

Total counts of bacteria and protozoa. Samples $(5 \mathrm{ml}$.) of rumen contents were removed and immediately diluted to $25 \mathrm{ml}$. with $10 \%(\mathrm{v} / \mathrm{v})$ formalin in $0.9 \%(\mathrm{w} / \mathrm{v})$ saline, and later diluted according to the size and number of organisms to be counted. 'Small' bacteria were counted in a $0.02 \mathrm{~mm}$. deep chamber observed under phasecontrast illumination, and 'large' bacteria in a $0.1 \mathrm{~mm}$. deep chamber after staining of the bacteria with methylene blue. Protozoa were counted in a I $\mathrm{mm}$. deep chamber made from glass slides cemented together with Araldite (I.C.I. Ltd.) and similar to the chamber described by Boyne, Eadie \& Raitt (1957). A known area of the chamber was defined by a standardized microscope eyepiece grid. Portions of the formolized samples were diluted with aqueous glycerol solution $(50 \%, \mathrm{v} / \mathrm{v})$ to give a suitable concentration for counting protozoa (Purser \& Moir, 1959; Boyne et al. I957). Preliminary investigations of all counting methods ensured that the techniques gave reproducible counts. 'Small bacteria' included all morphological types not counted as 'large bacteria'. These latter were defined as Quin's organism and large selenomonads (see for instance Moir \& Masson, 1952, for pictures of these.) Oscillospira and the unidentified large oval organism described by Eadie (I962a) ('Eadie's oval') were counted as seperate groups in the same manner as large bacteria. In counting small bacteria indeterminate clumps of organisms and debris were ignored and the few short chains of bacteria were counted as one organism. Protozoa were identified as far as genera and were grouped as 'large' (Polyplastron, Isotricha, Ophryoscolex), 'medium' (Entodinium bursa, Diploplastron, Dasytricha), and 'small' (small Entodinium species including $E$. caudatum).

Viable counts of bacteria. All media were prepared, inoculated and incubated under oxygen-free carbon dioxide, using techniques based on those of Hungate (1950) (Hobson \& Mann, 196I). The basal constituents of all three media, per I00 ml.: mineral solutions $a$ and $b, 15 \mathrm{ml}$. each; cysteine hydrochloride, $0.05 \mathrm{~g}$; resazurin, 0.000 I g.; agar, 2.0 g.; $\mathrm{NaHCO}_{3}, 0.4$ g.; centrifuged rumen fluid, $20 \mathrm{ml}$. Medium I contained in addition (per $100 \mathrm{ml}$.), Bacto Casitone, I.0 g.; Bacto Yeast Extract, 0.25 g.; sodium lactate $(70 \%, \mathrm{w} / \mathrm{v}), \mathrm{r} \cdot 0 \mathrm{ml}$.; glucose, $0.2 \mathrm{~g}$.; cellobiose, $0.2 \mathrm{~g}$.; maltose, 0.2 g. Medium 2 contained Bacto Casitone, I.0 g.; Bacto Yeast Extract, 0.25 g.; soluble starch (B.D.H.), 0.5 g. Medium 3 contained Bacto Casitone, 0.5 g.; Bacto Yeast Extract, $0 \cdot 125$ g.; cellulose powder (MN 300, Camlab (Glass) Ltd., Cambridge), $\mathrm{I} \cdot \mathrm{Og}$. The constituents of mineral solutions $a$ and $b$ and the methods of heat- or filter sterilizing the constituents of the media were described by Hobson \& Mann (I96I).

One-millilitre portions of the samples of rumen contents were taken by a widemouth pipette and successive tenfold dilutions prepared under $\mathrm{CO}_{2}$ in a diluting fluid of the composition of medium I with the agar omitted, $0 . \mathrm{I} \%(\mathrm{v} / \mathrm{v})$ Tween 80 (Honeywill and Stein, Ltd., London) added, the glucose concentration raised to $0.5 \%$ and the other sugars omitted. Half or one millilitre portions of the diluted rumen contents were added to suitable amounts of the media in $6 \times \frac{5}{8}$ inch test-tubes and roll tubes prepared. Three or four tubes for each of the appropriate dilutions $\left(10^{6}, 10^{7}, 10^{8}\right.$ for media $\mathrm{I}$ and 2 , and $10^{3}, 10^{4}, \mathrm{IO}^{5}$ for medium 3 ) were inoculated for counting. Cellulo- 
lytic colonies were identified by clearing of the cellulose powder around the colonies. All cultures were incubated at $38^{\circ}$; media I and 2 for 3 days; medium 3 for 4 weeks.

Morphological types of bacteria. Representative colonies were picked from the $10^{7}$ dilution cultures in media $I$ and 2 and Gram films prepared. Wet and dry preparations of the whole rumen contents were also examined at intervals.

In vitro fermentation rates of rumen contents were measured by a small-scale adaption of the manometric method described by El Shazly \& Hungate (1965) in which fermentative activity was measured by production of gas from a suspension of rumen contents (in the present case, ro g.) in minerals ( $a$ and $b$ ) + sodium bicarbonate $(\mathrm{I} .5 \%$, w/v, solution, $20 \mathrm{ml}$.). An excess of substrate ( $\mathrm{I} \mathrm{g} . \mathrm{MN} 300$ cellulose powder, rice starch or glucose) was added and gas production measured over $20 \mathrm{~min}$. incubation at $38^{\circ}$. A control without substrate was also included. Measurements were started within Io min. of removing the sample from the rumen.

Rumen $\mathrm{pH}$ values were determined from the sample immediately after collection.

Total volatile fatty acids were determined on samples, fixed in an $\mathrm{H}_{2} \mathrm{SO}_{4}+\mathrm{MgSO}_{4}$ mixture, by steam distillation and titration with standard alkali.

Ammonia nitrogen was determined on samples, fixed in $\mathrm{HCl}$, by a micro-diffusion method.

General procedure. Samples were taken from the various animals at intervals of I or $2 \mathrm{hr}$ during the $8 \mathrm{hr}$ period between the $8 \mathrm{a} . \mathrm{m}$. and $4 \mathrm{p} . \mathrm{m}$. feeds, usually starting at 9 a.m., to record 'diurnal' variations. 'Diurnal' in this text is used to describe the period between the morning and afternoon feeds, and not the daily period of $24 \mathrm{hr}$. The procedures were repeated at approximately weekly intervals to determine longer-term variations during any particular part of the experiments.

\section{RESULTS}

\section{Diurnal variations in numbers of organisms}

Total counts of small bacteria. Curves showing the diurnal variation in bacterial numbers are shown in Fig. I. Each curve is an average of a number of determinations. Six sets of observations were made over a period of 6 weeks on sheep 28 unfaunated (curve $a$ ). The maximum concentration of bacteria always occurred 4-5 hr after feeding, but the number at this time varied from $47 \times 10^{9}$ to $58 \times 10^{9} \mathrm{ml}$. over the 6 weeks. At $\mathrm{I} \mathrm{hr}$ and $7 \mathrm{hr}$ after feeding the variation in numbers was less. The presence of entodinia decreased the diurnal variation; curve $b$ is an average of three, weekly, observations where the number of bacteria at $5 \mathrm{hr}$ after feeding varied from about 35 to $40 \times 10^{9} / \mathrm{ml}$. The addition of Polyplastron to the rumen (Fig. I, curve $c$, which is an average of 4 sets of measurements) changed the whole pattern of diurnal variation to give a minimum bacterial concentration 3-4 hr after feeding (the minimal numbers varied from about $2 \mathrm{I}$ to $24 \times 10^{9} / \mathrm{ml}$. in the 4 samples). This pattern was similar to that found in sheep 27 with a mixed population of protozoa (Fig. I, curve $d$, which is an average of 5 observations, with minimum numbers varying from about 16 to $24 \times 10^{9} /$ ml.). These results also show variations in the average concentration of small bacteria taken over the whole feeding cycle in the presence or absence of protozoa.

Viable counts of bacteria. Figure $2(a-c)$ shows the diurnal variation in bacterial count obtained using three media. These counts can be most nearly correlated with the total counts of small bacteria, as it is known that Quin's organism, Oscillospira and 


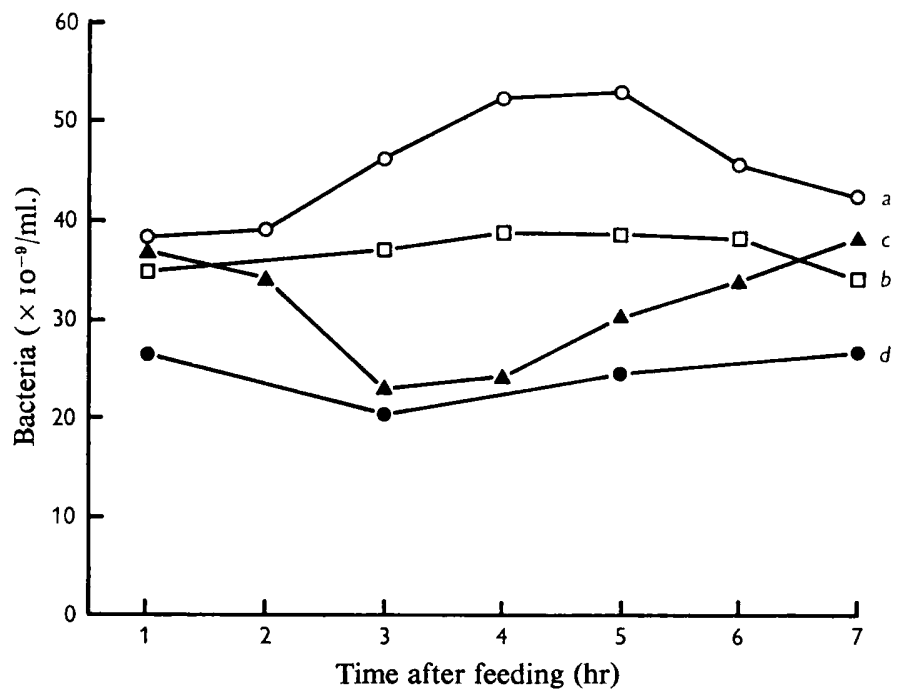

Fig. I. Diurnal variation in total small bacteria concentration in differently faunated sheep Sheep 28 (unfaunated), $\bigcirc$, curve $a$. Sheep 28 (Entodinium), $\square$, curve $b$. Sheep 28 (Entodinium

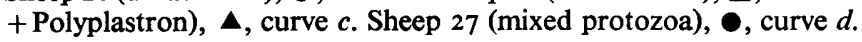
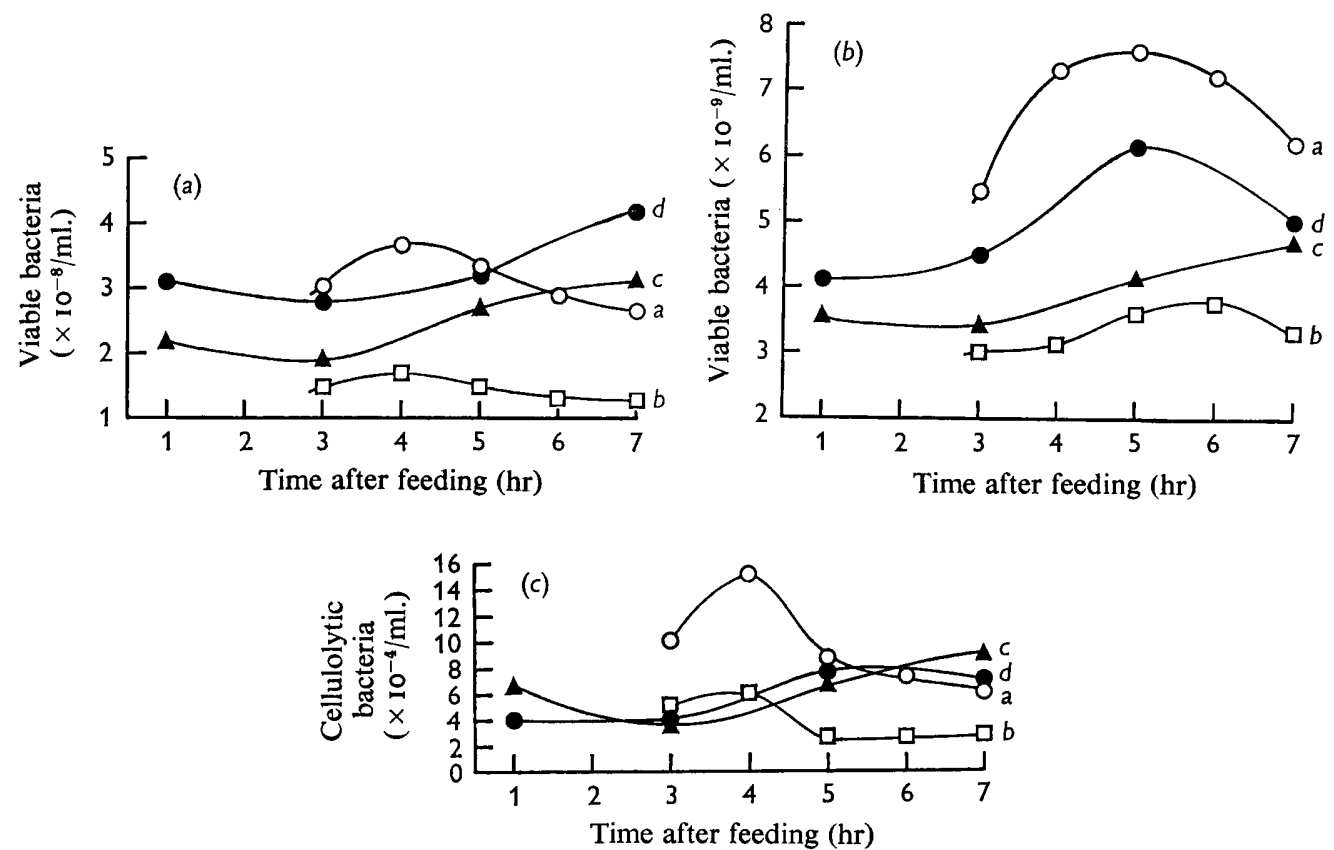

Fig. 2. Diurnal variation in viable counts of bacteria. (a) Medium I (non-selective). Sheep 28 (unfaunated), $\bigcirc$, curve $a$. Sheep 28 (Entodinium), $\square$, curve $b$. Sheep 28 (Entodinium + Polyplastron), $\Delta$, curve $c$. Sheep 27 (mixed protozoa), $\bullet$, curve $d$. (b) Medium 2 (starchcontaining), symbols as above. (c) Medium 3 (cellulose-containing), symbols as above. 
Eadie's oval organism do not grow on any of the media used, and although a serological relationship has been shown between the small selenomonads cultured on media such as number $I$ and the large selenomads seen in the rumen (Hobson, Mann \& Smith, 1962), it has not been shown uniquivocally that the large selenomonads can be cultured. Since only 2, or 3, sets of viable counts were done for each medium and each

Table I. Viable counts of bacteria in different media

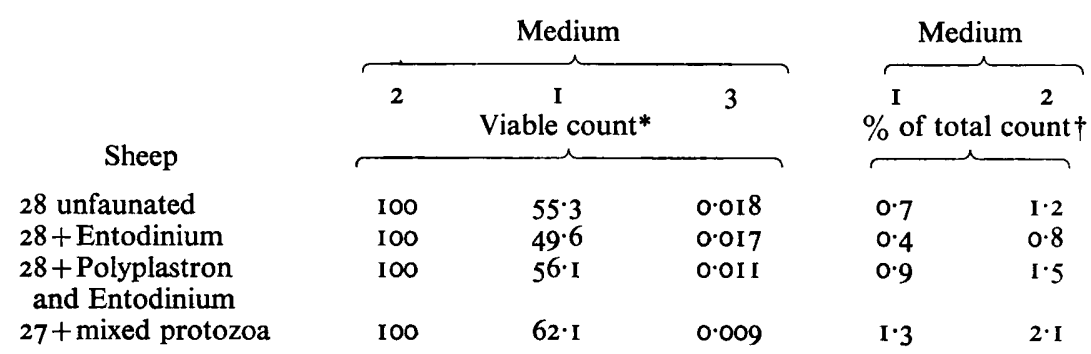

* Medium 2, starch containing; I, mixed sugars; 3, cellulose (see text). Count expressed as percentage of count in medium 2 . Averages of all determinations at $3 \mathrm{hr}$ after feeding.

$\dagger$ Representative figures, $3 \mathrm{hr}$ after feeding, from total and viable counts done on same sample. Other samples gave similar results.

Table 2. Percentage frequencies of counts of 'Eadie's oval' and Oscillospira in sheep with different fauna

\begin{tabular}{|c|c|c|c|c|c|c|c|c|}
\hline \multirow{3}{*}{$\begin{array}{l}\text { Cell numbers } \\
\left(\times 10^{-6} / \mathrm{ml} \text {. }\right.\end{array}$} & \multicolumn{8}{|c|}{ Organisms } \\
\hline & \multicolumn{4}{|c|}{ Eadie's oval* } & \multicolumn{4}{|c|}{ Oscillospira* } \\
\hline & $28 \dagger$ & $28 \mathrm{E} \ddagger$ & 28 PE§ & $27 \|$ & $28 \dagger$ & $28 \mathrm{E} \ddagger$ & 28 PE§ & $27 \|$ \\
\hline 80 & $8 \cdot 6$ & - & - & - & - & - & - & - \\
\hline $70-80$ & $5 \cdot 7$ & - & - & - & - & - & - & - \\
\hline $60-70$ & $5 \cdot 7$ & - & - & 一 & $2 \cdot 9$ & - & - & - \\
\hline $50-60$ & 8.6 & - & - & - & 2.9 & - & - & - \\
\hline $40-50$ & $8 \cdot 6$ & - & - & - & I4:7 & $38 \cdot 5$ & - & - \\
\hline $30-40$ & II $\cdot 4$ & 15.4 & - & - & $1 \mathrm{I} \cdot 8$ & 30.7 & - & - \\
\hline $20-30$ & $14 \cdot 3$ & 15.4 & - & - & $26 \cdot 5$ & $7 \cdot 7$ & 15.4 & - \\
\hline IO & $37 \cdot 1$ & $15 \cdot 4$ & $46 \cdot 2$ & $14 \cdot 3$ & $4 \mathrm{I} \cdot 2$ & $23 \cdot I$ & $84 \cdot 6$ & \\
\hline$\ll 10^{6} / \mathrm{ml}$ & - & 53.8 & 53.8 & 85.7 & - & - & - & 53.6 \\
\hline
\end{tabular}

* Percentage of total number of counts done on different days and at different times of day having a value as in left hand column. 70 counts of each organism were made.

$\dagger$ Sheep 28, no protozoa. ‡ Sheep 28, +Entodinium. \& Sheep 28,+Entodinium and Polyplastron. II Sheep 27, +mixed protozoa. - Nil.

sheep and the variation in counts was comparatively large, avarage counts would not be very significant, so one representative curve is shown in Fig. 2 for each sheep and each medium. The shapes of the curves were in all cases similar to those shown and the relative positions of the curves, with respect to counts, were similar. The maximum variation between counts done on different days was about $\mathrm{I} \cdot 5 \times 10^{8}$ bacteria $/ \mathrm{ml}$. for media $\mathrm{I}$ and 2 and for medium 3 about $\mathrm{I} \times \mathrm{IO}^{4} / \mathrm{ml}$. Medium I was designed to culture all types of rumen bacteria and similar media have been used by other workers to obtain complete viable counts (e.g. Bryant \& Robinson, I96I). However, the starchcontaining medium (medium 2 ) gave consistently higher counts than did medium I. It 
should be noted that this is a count of all bacteria growing in the medium, not just amylolytic bacteria. As zones of amylolysis spread rapidly throughout this medium (in the cultures examined the starch was completely hydrolysed after 3 days of incubation) it is usually impossible to say that a particular colony is amylolytic. This

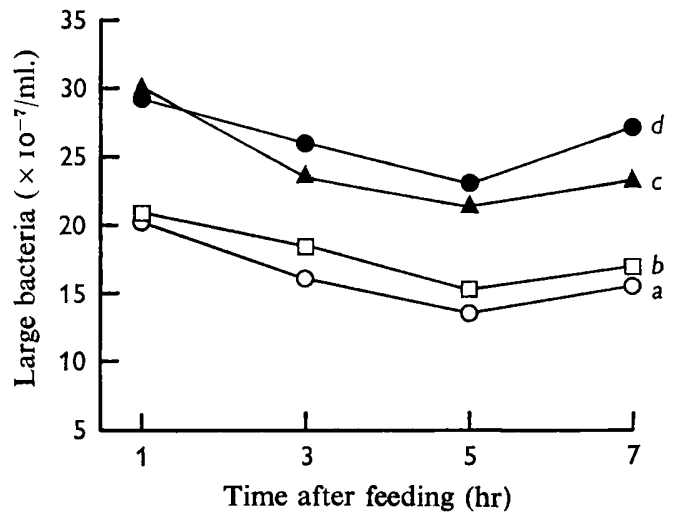

Fig. 3. Diurnal variation in total counts of large bacteria. Sheep 28 (unfaunated), $\bigcirc$, curve $a$. Sheep 28 (Entodinium), $\square$, curve $b$. Sheep 28 (Entodinium + Polyplastron), $\Delta$, curve $c$. Sheep 27 (mixed protozoa), $\bullet$, curve $d$.
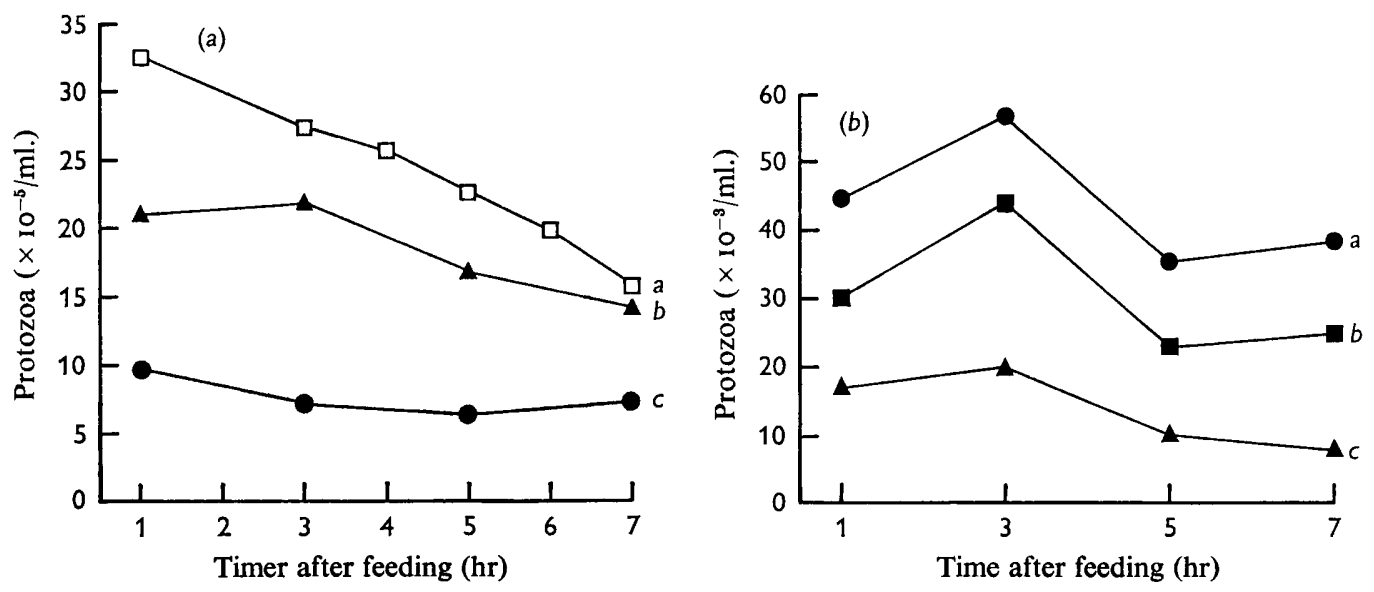

Fig. 4. (a) Diurnal variations in concentration of Entodinium. Sheep 28 (Entodinium), $\square$, curve $a$. Sheep 28 (Entodinium + Polyplastron), $\Delta$, curve $b$. Sheep 27 (mixed protozoa), $\bullet$, curve $c$. (b) Diurnal variations in concentration of 'large' ( $\boldsymbol{\theta}$, curve $a)$ and 'medium' ( $\boldsymbol{(}$, curve $b$ ) protozoa in sheep 27 (mixed protozoa) and Polyplastron ( $\triangle$, curve $c$ ) in sheep 28 (Entodinium + Polyplastron).

discrepancy in counts has been recently noted in investigations of sheep on other diets in these laboratories; but why it should be so cannot be stated at the present time. Theoretically any bacterium which will grow only on starch or starch hydrolysis products (such as Bacteroides amylophilus) should grow on the maltose in medium I, and the many non-amylolytic rumen bacteria should grow on medium 2 only by utilization of the maltose or glucose formed by the amylolytic bacteria or the small amount of glucose transferred with the diluting fluid inoculum. Also some bacteria, 
such as strains of ruminoccocci, cannot ferment either glucose or maltose, but should grow on the cellobiose in medium I. A more definite change in pattern of diurnal variation on introduction of ciliate protozoa into the rumen is shown in medium I than medium 2, and the pattern of medium $I$ is repeated in the counts of cellulolytic bacteria in medium 3. In our experience counts of cellulolytic bacteria in sheep have always been only a small fraction of the total viable count of bacteria and it may be that all cellulolytic bacteria are not counted in solid media such as number 3 . Zones of celluloysis vary from distinct to indefinite and the numbers of these latter are especially difficult to determine. Table I shows the number of bacteria growing in each medium when the number growing in the starch medium is counted as 100, and also the viable count in media $I$ and 2 as a percentage of the total count of small bacteria in the same samples.

Total counts of large bacteria. Figure 3 shows the diurnal variations in concentrations of 'large bacteria' (large selenomonads and Quin's organisms). In general the large bacteria varied in numbers from week to week to a much greater extent than did the small bacteria, for instance Fig. 3, curve $a$ is an average of 7 sets of observations where the minimum numbers varied from about 7 to $20 \times 10^{7} / \mathrm{ml}$. However, although the absolute concentrations varied, the shape of the curve was similar for each set of measurements.

Oscillospira and 'Eadie's oval'. This latter oval organism was described by Eadie (1962 a) and independently by Warner (1962) who counted it among the 'flagellates'; it was also seen by Abou Akkada \& El Shazly (1964). Following Warner (I966) it is referred to as 'Eadies' oval'.These organisms fluctuated considerably in numbers during the day and from day to day so that a good curve for diurnal variation could not be obtained. However, Table 2, which records the frequencies of appearance of the two organisms at different levels of concentration, shows that faunation, especially with more than one genus of protozoan, tended to decrease the average ruminal concentration of these organisms. Counts were made hourly during the day at similar times to those shown for other organisms, and were repeated on a number of days.

Total counts of ciliate protozoa. Although there was day-to-day variation in the concentrations of protozoa the curves for diurnal variations had a pattern characteristic of the state of faunation of each animal. The diurnal variations were determined during the periods when the protozoal populations had become stabilized. Figure $4(a)$ shows curves of diurnal variations in numbers of entodinia. Since the variation in numbers of protozoa from day to day was sometimes large, average numbers were not plotted and the curves are representative of 3-5 sets of observations at each stage of faunation. However, the positions of the curves relative to the numbers of protozoa are correct. The presence of other types of protozoa modified the curve obtained when entodinia were the only ciliates present in the rumen. Figure $4(b)$ shows the diurnal variations in numbers of the other groups of protozoa in the sheep at different times. In these cases the curves are similar in shape, and again they are representative of 3-5 sets of observations at each stage of faunation.

\section{Day-to-day variations in numbers of organisms}

The day-to-day variations in numbers during the periods when the previous measurements were made are shown in the figures. Figure $5(a-c)$ shows the numbers of small bacteria, large bacteria and entodinia in the rumen of sheep 28 at $4-5 \mathrm{hr}$ after feeding in 
the period after inoculation of the rumen with entodinia. A determination of numbers of bacteria was made I week before the inoculation, but the next determination was made 3 days after the inoculation. At 3 and 5 days after inoculation no entodinia were found in the counting chamber, although some were seen in undiluted rumen fluid, at 7 days an approximate count gave $0.2 \times 10^{5}$ entodinia $/ \mathrm{ml}$. The count at 9 days represents the first reliable count. It was not found possible to obtain accurate counts of entodinia in numbers lower than about $10^{5} / \mathrm{ml}$. by using lower dilutions of the original
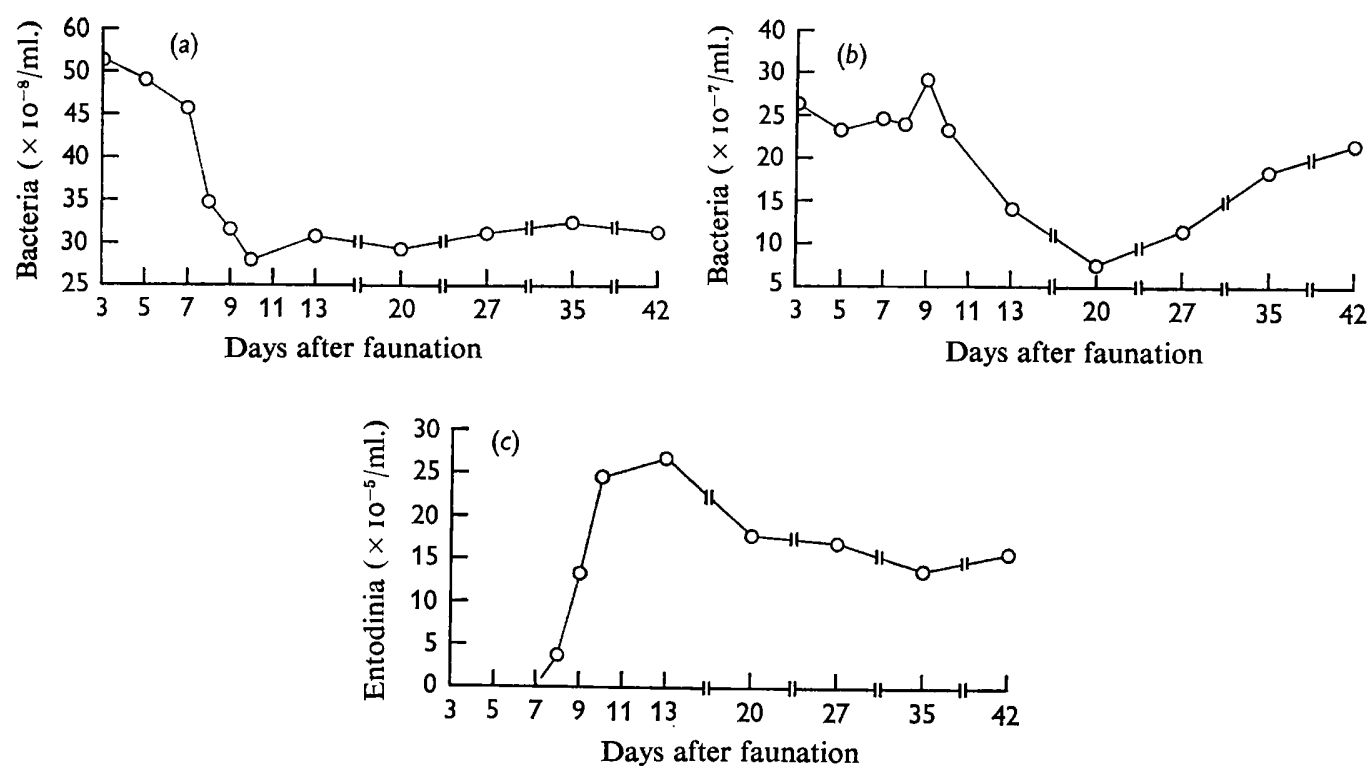

Fig. 5. Concentrations of small bacteria $(a)$, large bacteria $(b)$ and entodinia $(c)$ in sheep 28 after faunation with Entodinium. Counts at $4-5 \mathrm{hr}$ after feeding.
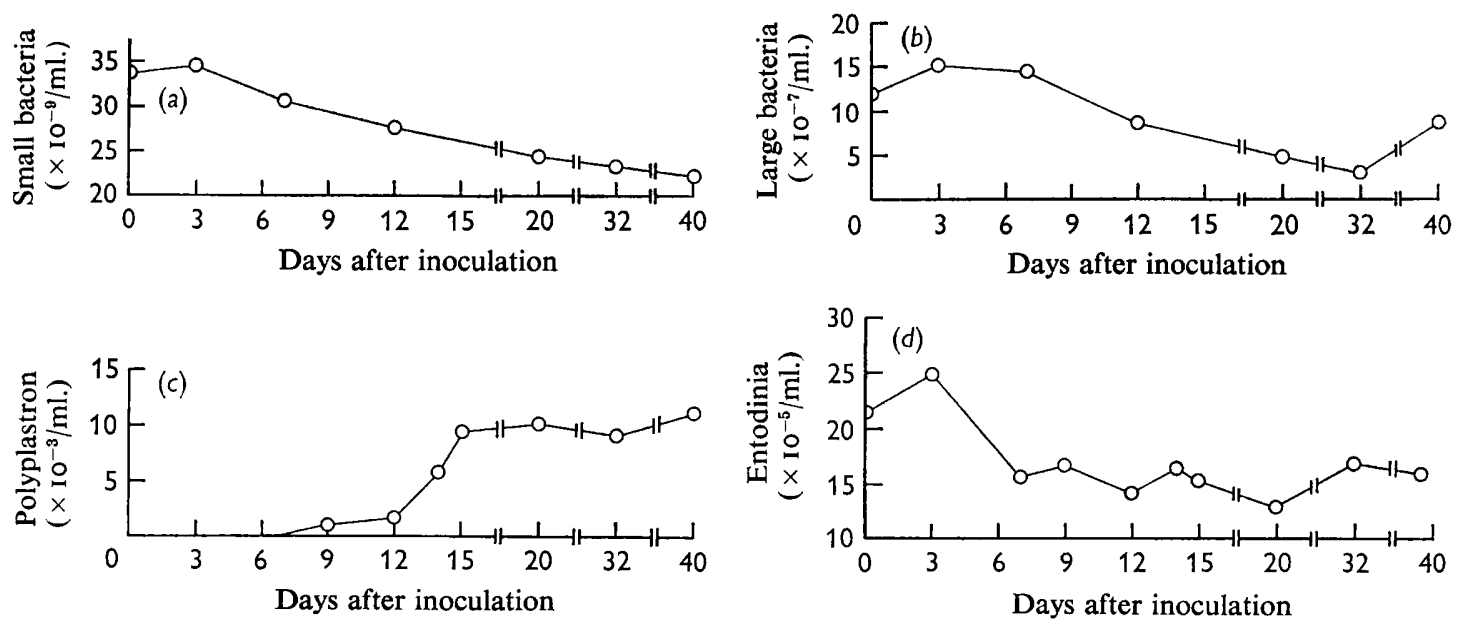

Fig. 6. Concentrations of small bacteria (a), large bacteria (b), Polyplastron (c) and Entodinium $(d)$ in sheep 28 after faunation with Polyplastron. Counts at $4-5 \mathrm{hr}$ after feeding. 
rumen contents in the $\mathrm{I} \mathrm{mm}$. deep cell as the background debris made it difficult to see the small protozoa.

Figure $6(a-d)$ shows the variations in numbers of small bacteria, large bacteria, Polyplastron and Entodinium in the period after inoculation of the rumen of sheep 28 with Polyplastron. Since Polyplastron is larger than Entodinium it is possible to see and count it in smaller dilutions of rumen fluid. However, Polyplastron, although seen at 7 days after inoculation, was not present in sufficient numbers for counting. One month elapsed between the last counts shown in Fig. 5 and the first counts in Fig. 6 and during this period the number of entodinia increased from about $16 \times 10^{5}$ to $2 \mathrm{I} \times 10^{5} / \mathrm{ml}$. During the same period the number of small bacteria also increased slightly whilst the number of large bacteria decreased.

During the period shown in Fig. 5 the numbers of Oscillospira fell during the first 7 days from $16 \times 10^{6} / \mathrm{ml}$. to $1 \cdot 2 \times 10^{6} / \mathrm{ml}$, then began to increase again until by the $35^{\text {th }}$ to 42 nd days they reached $18 \times 10^{6} / \mathrm{ml}$. By the beginning of the period shown in Fig. 6 , I month later, the number was down to $9.4 \times 10^{6} / \mathrm{ml}$. and from then it rose to $36 \times 10^{6} / 1$. at day 20 of this period and it fell then to $7 \cdot 2 \times 10^{6}$ by day 40 .

\section{Changes in morphological types of bacteria}

Gram-stained films of whole rumen contents show such a large number of bacteria of varied morphological types that it is often difficult to determine more than gross changes in the types of bacteria in films from different animals. Some 2000 Gram films of colonies growing in the $10^{7}$ dilution of rumen contents in media $I$ and 2 were therefore examined to see whether these gave a better indication of changes in bacterial population under the different conditions of faunation of the sheep. Tables were prepared showing the frequency of appearance of eleven morphological types of bacteria in the cultures. The II groups were as follows.

(I) Gram-negative: selenomonad types (crescent-shaped 'rods'); bacteroides types (pleomorphic rods); slender curved rods (Butyrivibrio, etc.); other Gram-negative rods; large and small cocci.

(2) Gram-positive: large and small rods; small, often pointed, streptococci, like Streptococcus bovis; tetracocci; large cocci; Gram-positive, or variable, small cocci (other than $S$. bovis).

(3) Spirochaete-type organisms.

Of these groups the most frequently encountered were the Gram-negative rods, Streptococcus bovis-type cocci and the small Gram-variable cocci, and these are mentioned here, but all the above morphological types were encountered in small numbers, although not in every culture. In general the bacteria growing in medium I and medium 2 were similar in types and numbers so the overall picture described below does not differentiate between media. In sheep 28 (without protozoa) the slender Gram-negative curved rods predominated with smaller numbers of bacteroides-like organisms, $S$. bovis-types and small Gram-negative and Gram-variable cocci. Few selenomonads were found. However, in sheep 28 (with entodinia) all four types of Gram-negative rods were present in similar numbers, with $S$. bovis-types being the only other frequently encountered organisms. When Polyplastron was added to the rumen of sheep 28 the four groups of Gram-negative rods were still present, and there was a large increase in Gram-variable small cocci, while $S$. bovis-type cocci were less frequently encountered. Spirochaete-type organisms were seen slightly more frequently. 
In sheep 27 the four types of Gram-negative rods were always present with bacteroidestypes tending to predominate. The only other group occurring at all frequently was the Gram-variable small cocci. $S$. bovis-types were present in only very small numbers. There was no obvious diurnal change in numbers of the various morphological types except for bacteroides-types in sheep 27 which tended to increase in numbers from the first to the seventh hour after the morning feed.

\section{In vitro fermentation rates}

The rates of in vitro fermentation of glucose, cellulose and starch were compared for each sheep under the different conditions of faunation. Again a number of observations were made at weekly intervals during the periods when the rumen populations
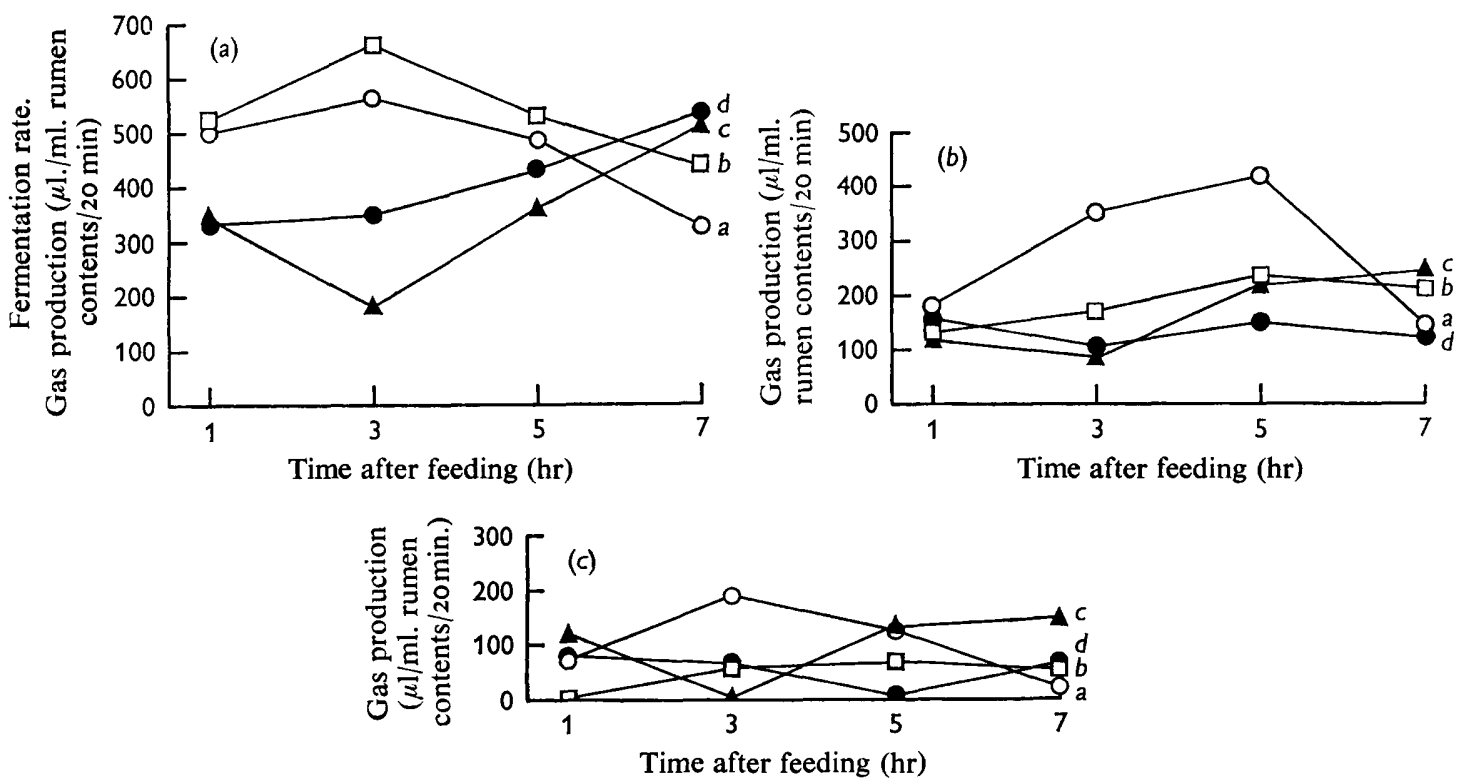

Fig. 7. In vitro fermentation rates of glucose $(a)$, starch, $(b)$ and cellulose, $(c)$. Sheep 28 (unfaunated), 0 , curve $a$. Sheep 28 (Entodinium), $\square$, curve $b$. Sheep 28 (Entodinium + Polyplastron), $\boldsymbol{\Lambda}$, curve $c$. Sheep 27 (mixed protozoa), $\bullet$, curve $d$.

of sheep 28 had become stabilized (e.g. from about I month after inoculation with entodinia) and average curves are shown in Fig. $7(a-c)$. In each case the gas production by the rumen contents alone has been subtracted. These rates represent short-term fermentations under conditions of substrate saturation and should give an indication of the maximum fermentative (or hydrolytic, if this is the rate-governing factor in starch or cellulose fermentation) capacities of the micro-organisms at any one time. The substrates are artificial in that they are not constituents of the feedstuffs and so do not represent the rates of fermentation of the similar feed constituents, but they enable a comparison to be made between the different rumen contents. Similar substrates have been shown to be degraded in vitro by rumen organisms, including the protozoa. 


\section{Rumen ammonia concentrations}

Diurnal changes in rumen ammonia concentrations are shown in Fig. 8. Each point represents an average value from a number of determinations made at intervals over the periods when the microbial populations had become stabilized. Sheep 27 was tested 7 times over a period of 9 months (i.e. near the beginning and end of the experiments on sheep 28). The shapes of the diurnal variation curves were similar at each time of sampling but the ammonia concentrations varied. The variation in concentration in sheep 27 at $3 \mathrm{hr}$. after feeding was typical of all points and was from about I 7 to $29 \mathrm{mg}$. $\mathrm{N} / \mathrm{IOOml}$. In sheep 28 (unfaunated) at $3 \mathrm{hr}$ after feeding 8 determinations varied from 8 to $13 \mathrm{mg}$. $/ 100 \mathrm{ml}$. In sheep 28 (with Entodinium) the variation at $3 \mathrm{hr}$ was from 18 to $24 \mathrm{mg}$. $100 \mathrm{ml}$. and in 28 (with Entodinium and Polyplastron) from $2 \mathrm{I}$ to $27 \mathrm{mg}$./100 ml.

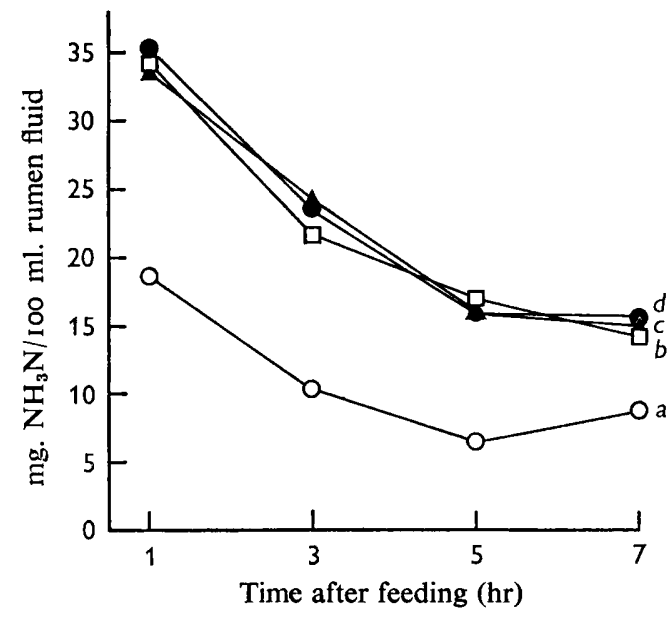

Fig. 8

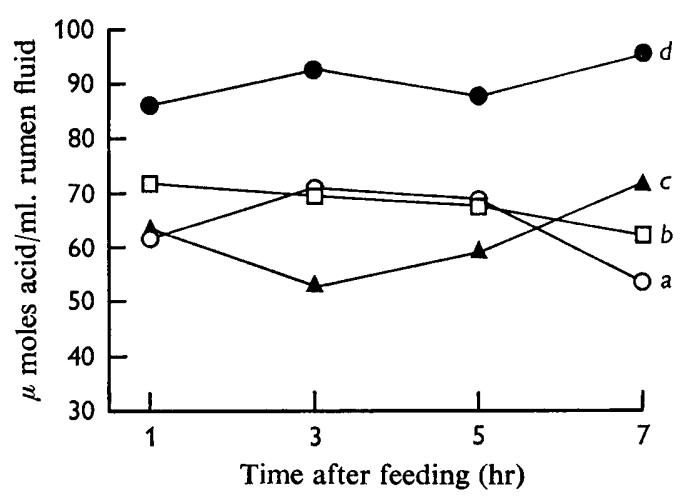

Fig. 9

Fig. 8. Diurnal variations in rumen ammonia concentration. Sheep 28 (unfaunated), $\bigcirc$, curve $a$. Sheep 28 (Entodinium), $\square$, curve $b$. Sheep 28 (Entodinium+Polyplastron), $\Delta$, curve $c$. Sheep 27 (mixed protozoa),, , curve $d$.

Fig. 9. Diurnal variations in rumen volatile fatty-acid concentration. Sheep 28 (unfaunated) $\bigcirc$, curve $a$. Sheep 28 (Entodinium), $\square$, curve $b$. Sheep 28 (Entodinium + Polyplastron) $\Delta$, curve $c$. Sheep 27 (mixed protozoa) $\bullet$, curve $d$.

\section{Rumen volatile fatty acid concentration}

Figure 9 shows the diurnal changes in total volatile fatty acids in the different sheep. Again the points are avarages of a number of determinations which gave curves of similar shape. Taking the variation in concentration at $3 \mathrm{hr}$ after feeding as typical, in sheep 28 (unfaunated) this was from about 60 to $83 \mu$ mole $/ \mathrm{ml}$. In sheep 28 (with Entodinium) it was $64-75 \mu \mathrm{mole} / \mathrm{ml}$. In sheep 28 (with Entodinium and Polyplastron) it was from 48 to $6 \mathrm{r} \mu \mathrm{mole} / \mathrm{ml}$., and in sheep 27 from 83 to $97 \mu \mathrm{mole} / \mathrm{ml}$.

\section{Rumen $\mathrm{pH}$ values}

In each animal, or at each stage of faunation, the rumen $\mathrm{pH}$ values varied little during the period between feeds. There was a slight tendency for a minimum $\mathrm{pH}$ value 
to occur $4-5 \mathrm{hr}$ after feeding. In the case of sheep 28 (unfaunated) a number of determinations gave maximum and minimum average values of $\mathrm{pH} 6 \cdot 6$ and $6 \cdot 4$. In sheep 28 (with Entodinium) the values were $\mathrm{pH} 6.6$ and 6.5. In sheep 28 (with Entodinium and Polyplastron) they were pH 6.8 and 6.6, and in sheep 27, 6.5 and 6.3.

\section{DISCUSSION}

Although the rumen provides a form of continuous culture this probably never attains a true steady state in the sense in which the term is used of the laboratory continuous culture of one organism. However, the rumen flora is built up by degrees by inoculation of the animal from external sources-air-borne organisms, contaminated feedstuffs, and contact with other animals-and these inocula form a population in which a large number of the organisms form a more or less stable population and the others form only a transient population of insignificant number. The constituents of this population are to a large extent conditioned by the feed of the host animal. However, even when the feed is of constant composition the organisms are subject to several influences which cause variations in their concentrations. Nutrients for the organisms are added intermittently in the form of the feed of the host animal. The flow of saliva, which acts as a diluent and buffer in the rumen, fluctuates, partly in response to the feeding regime. The influences of the type of feed and the frequency of feeding on the concentrations and kinds of rumen organisms have been the subject of a number of investigations (for a review see, for instance, Hungate, 1966). Less attention has been paid to interactions between the organisms themselves, although it is known that such interactions do occur. For instance, Eadie (1962b) noted antagonism between species of ciliate protozoa. For example, in an animal on a constant feeding regime Polyplastron multivesiculatum will become dominant over other large Ophryoscolecids, and this has been shown to be due to predation. This dominance, however, has not been shown towards Entodinium species. Similarly, in vitro experiments have shown that many, perhaps all, species of rumen ciliates ingest bacteria (reviewed by Hungate, 1966), although here the comparatively rapid division rate and large numbers of bacteria present in the rumen make it unlikely that one species of bacterium would be completely eliminated by protozoal predation. However, it has been shown that there is a significant decrease in the total bacterial concentration in the rumen when a mixed population of protozoa is established in a previously unfaunated rumen (Eadie \& Hobson, 1962). This decrease in bacterial numbers may be caused by the abovementioned predation of protozoa on the bacteria, or it may be caused by the competition for nutrients (or 'space') between the organisms. The experiments described here were done in an attempt to throw further light on the relationship between the ruminal bacteria and protozoa. The animals used were reared in an identical manner and were fed the same ration at the same time each day in order to eliminate as far as possible any variations in the rumen organisms caused by external influences. The volumes of rumen digesta should have been similar in all animals so that variations in concentrations of micro-organisms or metabolic products should reflect changes in the total rumen activity. Of the two major possibilities of interaction between the bacteria and protozoa, bacterial ingestion by the protozoa might be either selective or unselective. The early experiments of Gutierrez on bacterial ingestion by the holotrich and Entodinium protozoa suggested that ingestion was selective on morphological grounds. 
(Gutierrez, 1958; Gutierrez \& Hungate, 1957; Gutierrez \& Davis, 1959). However, later experiments by Coleman (1964) on Entodinium caudatum cultured in vitro suggested that ingestion was non-selective and that the number of bacteria ingested was proportional to their size. The number of species of bacteria in the rumen is large, and there is very great strain variation amongst the known species. It was thought that it would be an almost impossible task to determine whether a particular species of bacterium was being ingested by the protozoa, but since the only suggestion of selective bacterial feeding by the protozoa has been selection on morphological grounds it was thought that the study of the broad morphological groups of bacteria in the rumen with and without protozoa might show selective bacterial ingestion if it occurred, or might indicate a completely non-selective ingestion. Ingestion of bacteria by the protozoa might take place only at certain stages in the protozoan feeding or metabolic cycle and so diurnal variations in numbers of organisms were studied.

The case of competition for nutrients between bacteria and protozoa is more difficult to substantiate. As comparatively little is known about the nutritional requirements of the protozoa, and especially of their nitrogen metabolism, it seemed that competition might only be established on the basis of the carbohydrate metabolism of the organisms. Entodinium caudatum was the first protozoan established, as this is known to ferment mainly starch. It might therefore compete with starchfermenting bacteria for substrate and this it was hoped might be reflected in viable counts of bacteria on a starch-containing medium. Entodinia have also been said to ingest Gram-positive streptococci ( $S$. bovis) (Gutierrez \& Davis, 1959) or to ingest completely non-selectively (in vitro)(Coleman, 1964). It was hoped that the experiments might distinguish between these extremes under in vivo conditions. The second protozoan added to the rumen was Polyplastron multivesiculatum. This ferments starch (Abou Akkada et al. 1963) and might be expected to compete both with the entodinia and with starch-fermenting bacteria, if nutrient competition existed. It also ferments cellulose (Abou Akkada et al. 1963) and so a second possibility for competition existed, with the cellulolytic bacteria. Finally the rumen flora of a sheep containing a mixture of many protozoal species, such as is found normally in the rumen, was studied to see if further interactions of the organisms could be determined. Other measurements were made to see whether the presence or absence of protozoa had any gross effect on some aspects of the rumen metabolism of most importance to the overall metabolism of the host animal. All measurements were started $\mathrm{I} \mathrm{hr}$ after the morning feed as at that time any residual food was removed and weighed back. Also the main increase in salivary flow due to eating would have ceased by the end of the hour. Rumen conditions therefore would by then have settled.

Figure $\mathrm{I}$ shows the changes in diurnal pattern of variation of concentration of small bacteria. The pattern (curve $a$ ) in the unfaunated sheep shows a distinct maximum in concentration at 4-5 hr after feeding. The presence of entodinia decreases the average number of bacteria and also markedly decreases the peak concentration. Coleman (I964) found that Entodinium caudatum, in vitro, could ingest 12,000 Escherichia coli per protozoan per hr. If the rate of uptake of bacteria by the number of E. caudatum present in sheep 28 (Entodinium), which is about $25 \times 10^{5}$ per $\mathrm{ml}$., were of this same order, then it could be calculated that the protozoa could when most active almost completely nullify the increase in rumen bacterial population due to division of the bacteria. The changes in concentration of viable bacteria cultured on medium I 
which should be non-selective, are similar in pattern (Fig. 2(a), curves $a$, and $b$ ). However, viable bacteria are a smaller percentage of the total in sheep 28 (with entodinia) than they are in the unfaunated sheep (Table I). Since the numbers of viable bacteria are greatest during the period $3-5 \mathrm{hr}$ after feeding these results taken together suggest that a selective ingestion of viable bacteria by the entodinia was taking place, although the fact that the concentration of entodinia falls during the whole inter-feeding period (Fig. 4a) suggests that the protozoa were not actively dividing at this time, and were being washed out by saliva flow through the rumen. Warner (1962) found in sheep fed once a day that maximum concentrations of dividing entodinia were present at about $16 \mathrm{hr}$ after feeding. If conditions in the present experiments were similar this suggests that the period under consideration was too short for entodinia to divide and that most division would occur during the early morning period before $8 \mathrm{a} . \mathrm{m}$. feed. Ingestion of viable bacteria by the entodinia may not be selection of viable bacteria as such, but may be due to ingestion of starch granules with a large number of adherent viable bacteria (rapid ingestion of starch granules by the entodinia was observed microscopically in the first I-2 hr after feeding). Minato, Endo, Ootomo \& Uemura (1966) showed that, as might be expected a somewhat higher proportion of viable (i.e. culturable) bacteria was attached to the solids part of the rumen contents of a hay and concentrate-fed sheep than was present in the bacteria 'free' in the rumen fluid. When Polyplastron were added to the rumen organisms there was a greatly altered pattern of diurnal variation of total and viable bacteria, the curves for both these functions showing a definite minimum at 3-4 $\mathrm{hr}$ after feeding (Fig. I, curve $c$, Fig. $2(a)$, curve $c$ ). At $3 \mathrm{hr}$ after feeding the concentration of Polyplastron was slightly greater than at I hr (Fig. 4(b), curve $c$ ), which would indicate that multiplication of the organisms was taking place. Microscopic examination showed rather larger numbers of dividing Polyplastron at about $4 \mathrm{hr}$ after feeding than in the first hour or two. The coincidence of this maximum in numbers of Polyplastron and minimum in numbers of bacteria suggests that Polyplastron were ingesting bacteria, but mainly at the same time when Polyplastron were dividing, since later the numbers of Polyplastron decreased and the numbers of bacteria increased. The percentage of viable bacteria (compared with the total numbers) at this time returned to a similar figure to that in the unfaunated sheep (Table I). It might be inferred that Polyplastron ingested both live and dead bacteria, and possibly more dead than live ones, (by ingestion of more of the 'free' bacteria than 'fixed' ones) as the entodinia would still have some effect, although they were in smaller numbers than when present alone (Fig. $4 a$ ). Since the total concentration of bacteria at the beginning and end of the inter-feeding period is similar whether entodinia alone or entodinia and polyplastrons are present, although there were much lower numbers at $3-5 \mathrm{hrin}$ the latter case, it would appear that the polyplastrons are, over a limited time, much more active in ingesting bacteria than are entodinia. Although the smaller effect of entodinia alone on the concentration of bacteria (Fig. I, curve $b$ ) might be partly explained by the fact that the numbers of entodinia are constantly decreasing over the inter-feeding period. Competition for nutrients alone would appear to be ruled out, especially in the case of Polyplastron, as the decrease in numbers of bacteria between 2 and $3 \mathrm{hr}$ after feeding (Fig. I, curve $c$ ) is much greater than could be accounted for by a decrease in growth rate of the bacteria and consequent washout from the rumen. No figures were obtained for the rate of washout of a marker substance from the rumen of this sheep, but 
Blackburn \& Hobson (1960) found, for a sheep fed on a more artificial roughageconcentrate diet, that polyethyleneglycol washed out of the rumen exponentially at a rate of $7 \cdot 3 \% / \mathrm{hr}$ between $\mathrm{I}$ and $7 \mathrm{hr}$ after feeding. The fall in concentration of Entodinium when alone was of the same order as this (Fig. 4(a), curve $a$ ), suggesting that this was due to washout of non-dividing organisms. In no case can the change in concentration of protozoa either diurnally or between different states of faunation be due to $\mathrm{pH}$ effects as the $\mathrm{pH}$ values were never low enough to affect growth of the organisms.

When a population of a number of species of protozoa was present (sheep 27), then the total counts of bacteria were lower than in the other sheep at all times during the inter-feeding period, and the curve for diurnal variation showed a small decrease between I and $3 \mathrm{hr}$ (Fig. I, curve $d$ ). Polyplastron in sheep 27 were present in smaller numbers than in sheep 28 (Entodinium + Polyplastron), (about $10.6 \times 10^{3} / \mathrm{ml} .3 \mathrm{hr}$ after feeding, see Table 3 and Fig. $4(b)$, curve $c$ ), and so would not have as great an effect as they had in sheep 28 , assuming that they were here the main cause of the rapid fall in concentration of bacteria (Fig. I, curve $c$ ). In the experiments of Eadie \& Hobson (1962) the average difference in total small bacterial count (at $3 \mathrm{hr}$ after feeding) between two unfaunated and one faunated sheep over a period of 16 months was $1 \cdot 3 \times 10^{10} / \mathrm{ml}$. The present counts in sheep 27 and 28 agree quite well with these figures, allowing for the fact that the ration fed to the previous sheep with its rather different ratio of hay to concentrates may have given a different diurnal variation in counts. In the graphs representing the diurnal variations in protozoal numbers it is of interest that the presence of other protozoa modified the diurnal variation in numbers of entodinia (Fig. 4a), and it would appear that the division cycle altered as these protozoa no longer washed out during the inter-feeding period. There appears to be no obvious explanation of this. In mixed populations of protozoa the concentrations of entodinia were considerably smaller than when entodinia were present alone. This was probably not due to predation on entodinia by other protozoa, but may be a reflexion of competition for nutrients. Results from sheep 28 (Polyplastron + Entodinium) showed that Polyplastron does not ingest Entodinium to any great extent. Entodinium caudatum appear to live largely by fermentation of starch and this might be competed for by the other protozoal species although these have other sources of fermentation energy. The fall in numbers of Polyplastron between sheep 28, where it was present with Entodinium, and sheep 27, where it was in a mixed population, is not so great as that of Entodinium. Polyplastron can attack a diversity of carbohydrate substrates. Of course, other possibilities of protozoal competition may exist. The shape of the curve for diurnal variation in concentration of Polyplastron was similar whatever other protozoa were present and in turn was similar to the curves for all the protozoa (other than entodinia in sheep 28 and sheep 27) in that a maximum concentration occurred about $3 \mathrm{hr}$ after feeding. The curves do vary, though, round about 5-7 hr after feeding, and occasional counts done at $8 \mathrm{hr}$ (just before the second feed) showed that the upward or downward trend at $7 \mathrm{hr}$ (Fig. $4 a, b$ ) was continued.

In Fig. Io are plotted some of the figures obtained for concentration of small bacteria in the sheep at different states of faunation, against the approximate volumes of the protozoal populations at these same times. It will be seen that the numbers of bacteria decreased with increasing volume of ciliates, and it would seem most likely that this was due to ingestion of bacteria. The figures of Coleman (1964) suggest that 
Entodinium caudatum can in vitro ingest bacteria to a very large proportion of the total volume of the protozoal cell. Coleman obtained maximum and minimum volumes for bacteria ingested in a number of experiments of $2.2 \times 10^{4} \mu^{3}$ and $8 \times 10^{3} \mu^{3}$ per $E$. caudatum cell. Assuming that the volume of a small bacterium is $\mathrm{I} \cdot 5 \mu^{3}$ then the decrease in bacterial volume is similar to the increase in protozoal volume when the

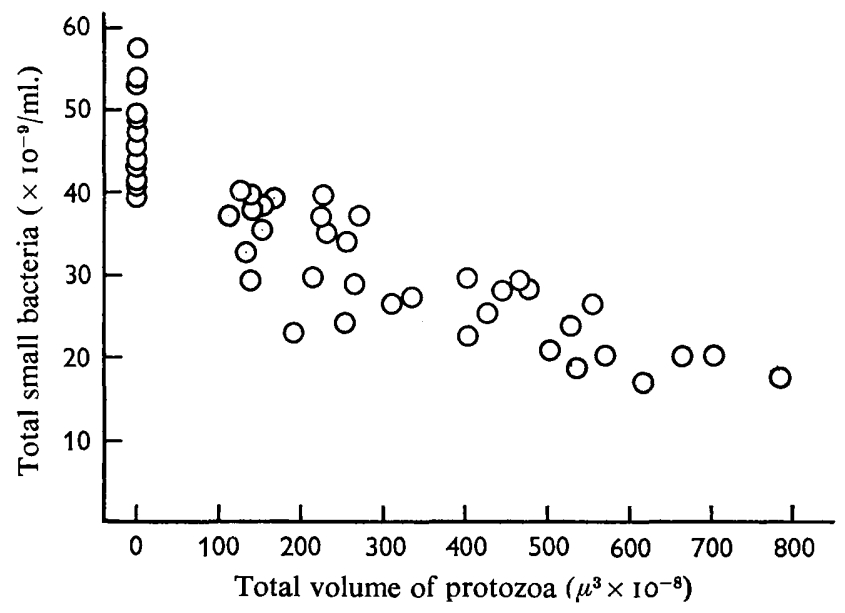

Fig. 10. Comparison of small bacterial concentrations and estimated approximate volumes of protozoa in differently faunated sheep taken from counts at 3,5 and $7 \mathrm{hr}$ after feeding, and on different days. Volumes of protozoa taken as: small protozoa (including Entodinium), ${ }^{1} 0^{4} \mu^{3}$; medium protozoa, $5 \times 10^{4} \mu^{3}$; large protozoa, $10^{6} \mu^{3}$.

Table 3. Diurnal variations in concentration of certain species of protozoa in the mixed protozoal population of sheep 27

Time after feeding (hr)

\begin{tabular}{|c|c|c|c|c|}
\hline \multirow{2}{*}{ Protozoan } & \multicolumn{4}{|c|}{ Number of protozoa $\left(\times \mathrm{IO}^{-3} / \mathrm{ml}.\right)$} \\
\hline & $\mathbf{I}$ & 3 & 5 & 7 \\
\hline Isotricha & II $\cdot 3^{*}$ & 13.3 & $4 \cdot 7$ & $6 \cdot 1$ \\
\hline Dasytricha & $2 \mathrm{I} \cdot 4^{*}$ & $21 \cdot 9$ & II 0 & II 3 \\
\hline Polyplastron & $9.0 \dagger$ & $10 \cdot 6$ & $3 \cdot 2$ & $5 \cdot 8$ \\
\hline
\end{tabular}

* Averages of 4 sets of counts. $†$ One count.

latter is small, and in this case the protozoal volume figures are mainly from sheep 28 with only entodinia present. At higher protozoal volumes (when mixed protozoal populations were present) the decrease in bacterial volume is much less than the increase in protozoal volume. This suggests that (in conformity with Coleman's, 1964, results) entodinia can ingest bacteria to a volume almost that of the protozoan, while in the larger protozoa the volume of bacteria ingested is much less than the cell volume.

However, if the viable counts on the starch-containing medium 2 reflect the numbers of starch-hydrolysing bacteria (see later; in vitro fermentations) then there is some suggestion of preferential ingestion of starch-hydrolysing bacteria by Entodinium and 
Polyplastron, as the maximum concentration of bacteria growing in medium 2 is moved from about $5 \mathrm{hr}$ to $6 \mathrm{hr}$ or more after feeding when Entodinium or Polyplastron are added to the rumen (Fig. $2 b$ ) and these latter times correspond to the lowest inter-feeding concentrations of the protozoa. This 'selective' ingestion may not be selective for bacteria as such but may reflect the ingestion by the protozoa of starch granules with adherent starch-hydrolysing bacteria. Although almost all the species of protozoa in sheep will ingest starch granules the reversal of the trend to a later peak of starch-hydrolysing bacteria shown in heep 27 may be a reflexion of the much decreased numbers of very actively starch-ingesting Entodinia in this sheep as compared to sheep 28 .

The changes in diurnal rhythm of the cellulolytic bacteria are similar to those of the total viable bacterial count (medium I) (Fig. $2 a, c$ ) and presumably reflect nonselective ingestion of bacteria by the protozoa. There is no suggestion of competition between cellulolytic Polyplastron and the cellulolytic bacteria.

The identification of the principal morphological types of bacteria present with the different protozoal populations does not on the whole suggest any selection by the protozoa of bacteria on morphological grounds. In fact the presence of rather more Streptococcus bovis-type bacteria in sheep 28 (with entodinia) than in sheep 28 (unfaunated) would appear to be evidence against the previously reported ingestion of S. bovis by Entodinium (Gutierrez \& Davis, 1959). However, S. bovis largely disappeared in the rumens containing Polyplastron + Entodinium and the mixed protozoal population. In the case of the Gram-negative rod-type bacteria, they appear to be more evenly distributed in cultures from the faunated sheep than the unfaunated. Small selenomonads, in particular, were more prominent in cultures from the faunated sheep. The fact that curved Gram-negative rods became less prominent after faunation may be a reflexion of their initially larger proportion of the flora. The generally more frequent appearance of the other Gram-negative rods may be a reflexion of better rumen conditions for growth, although it is difficult to say what these conditions are. Coleman (1964) found that when Entodinium caudatum ingested Escherichia coli labelled with ${ }^{14} \mathrm{C}$ amino acids, the amino acids were incorporated into protozoal protein after digestion of the bacteria, and also that some of the hydrolysed bacterial protein was 'washed out' of the protozoa into the surrounding medium. If this process takes place in the rumen then this would not only recycle amino acids for use in bacterial growth but also provide more amino acids for bacterial deamination, and thus tend to increase the ruminal ammonia concentrations. Our own experience with selenomonads suggests that all strains need animo acids for growth and they could be provided in this way, whilst the increased concentration of rumen ammonia in the faunated sheep might tend to favour growth of Bacteroides-type bacteria, as, for instance, Bacteroides amylophilus utilizes mainly ammonia as nitrogen source (Blackburn, 1965; Hobson \& Summers, 1967) and B. succinogenes utilizes ammonia in preference to amino acids (Bryant, Robinson \& Chu, 1959). It seems unlikely that the higher volatile fatty acid concentration in the faunated sheep would stimulate growth of the Gram-negative rods. Theincreased propionic acid concentration found in faunated sheep (Abou Akkada \& El Shazly, I964; Christiansen, Kawashima \& Burroughs, 1965; Luther, Trenkle \& Burroughs, 1966) may be related to the increased proportions of selenomonads and Bacteroides-type bacteria found in the present faunated sheep. Selenomonas ruminantium strains produce lactic and, sometimes, succinic acids. 
Bacteroides ruminicola, B. amylophilus, B. succinogenes and Succinimonas amylolytica (which morphologically would come in this group) all produce large amounts of succinic acid and both lactic and succinic acids are precursors of propionic acid in the rumen fermentation.

The numbers of 'large bacteria' (large selenomonads and Quin's ovals) in these sheep were on average similar to those previously found by Eadie \& Hobson (I962) However, in both cases large day-to-day variations in numbers were found. In the present experiments the only reproducible result was the shape of the curve for diurnal variations in numbers. The curves in Fig. 3 are typical and are averages from a number of determinations where the population of organisms seemed stabilized for some days, but consideration of Fig. 5 and 6 will show that they do not truly indicate the relative concentrations of the large bacteria over a long period, and in fact when the concentrations of large bacteria at any one time after feeding are plotted against days on the experiment for sheep 28 it is found that the concentrations increase and decrease periodically without reference to the protozoal population. For instance in sheep 28 (with Polyplastron and Entodinium) the concentration of large bacteria continued to increase after 40 days (Fig. $6 \mathrm{~b}$ ) reaching about $23 \times 10^{7} / \mathrm{ml}$. at 50 days, $24 \times 10^{7} / \mathrm{ml}$. at 57 days, and $20 \times 10^{7} / \mathrm{ml}$. at 64 days. These numbers were similar to those found at the peaks of concentration during the period preceding faunation with Entodinium. There is thus no discernible influence of faunation on the concentration of large bacteria. What appear to be interactions in Fig. 5 and 6, e.g. (Fig. $5 b, c$ ) the rapid decrease in numbers of large bacteria from days 9 to 13 where the concentration of entodinia is increasing rapidly, are entirely fortuitous, and this does emphasize the fact that even in a comparatively constant environment such as the rumen observations should be continued over a prolonged period to provide reasonable data on the state of the microbial population.

However, the curves for small bacteria and protozoa (Fig. 5a, $c ; 6 a, c$ ) do show definite evidence of interaction in that, although there are some day-to-day variations the number of bacteria is decreased by the presence of protozoa, and this decrease coincides with the development of the protozoal populations. The 'overshoot' of numbers of entodinia at about 12 days after their introduction, before they settle down to a stable population, is similar to that found when a bacterial population is developing from a small inoculum in an in vitro continuous culture.

The in vitro fermentation rates of different substrates are shown in Fig. 7. These should give an indication of the maximum fermentative capacity of the bacteria and protozoa, but this need not be strictly correlated in magnitude with either the total numbers of organisms or the numbers of viable bacteria. Viable bacteria will be fermentative in these experiments, but the status of the 'non-viable' ('non-culturable') bacteria is obscure. Somenon-culturable bacteria amy still ferment sugars. The shapes of the curves for fermentation of glucose (Fig. 7a) are quite similar to the diurnal variation curves of the total small bacteria and the viable counts in medium I (Fig. I; 2a). This suggests that most of the fermentative capacity of the rumen organisms under these conditions is due to the bacteria. The in vitro fermentation of starch (Fig. $7 b$ ) gives a different pattern of diurnal variation and this corresponds quite well with the viable counts on the starch medium 2 (Fig. $2 b$ ). This supports the suggestion made earlier that the viable counts in medium 2 are related to the numbers of starch-fermenting bacteria, and also again suggests that the in vitro fermentation is mainly a product of 
bacterial metabolism. In vitro cellulose fermentation is small, as are the viable counts of cellulolytic bacteria, and it seems unwise to make any deductions from the shape of the curves for diurnal variation in this case. In all fermentations all species of the protozoa remained motile at the end of the incubation period.

The curves for diurnal variation in rumen ammonia and volatile fatty acid concentrations are shown in Figs. 8 and 9. Although there was day-to-day variation in these concentrations the ammonia concentration in the faunated animals was always higher than in the unfaunated animals (Fig. 8). This agrees with the observations on faunated and unfaunated sheep made by Abou Akkada \& El Shazly (1964). Luther, Trenkle \& Burroughs (1966) have also demonstrated an increase in ammonia production when a washed suspension of mixed rumen protozoa was added to an in vitro fermentation system containing only rumen bacteria. However, the shape of the diurnal variation curve at each state of faunation does not vary, and is not altered to coincide with diurnal variation curves for any of the protozoa, also there is no difference in ammonia concentrations between the animals with different protozoal populations. If the protozoa produce ammonia then it must be concluded that all species do so; or that, perhaps in the way previously suggested, bacterial ammonia production is enhanced by the presence of protozoa. This latter possibility was also suggested by Purser \& Moir (1966). The gradual decline in ammonia concentration from about $\mathrm{I} \mathrm{hr}$ after feeding is probably a reflexion of the presence of substrate leading to ammonia formation in the period after feeding and then the gradual utilization of this ammonia by bacterial growth and removal of it from the rumen by absorption or passage to the omasum.

The curves for volatile fatty acid concentrations (Fig. 9) support the observations of Abou Akkada \& El Shazly (1964) and Christiansen et al. (1965) in that volatile fatty acid concentration was higher in the sheep (27) with a mixed ciliate population than in the unfaunated sheep (28). The diurnal variations are also smoothed out. The much increased concentration of VFA in sheep 27 is somewhat difficult to understand though, unless the protozoa produce more VFA than an equivalent volume of bacteria, which does not seem likely. The proportion of viable bacteria is greater in sheep 27 than 28 (unfaunated; Table I), although the total numbers are less. This may indicate some stimulation of bacterial metabolism by the protozoa, such as was suggested for ammonia formation. If substrates are not limiting then ingestion of bacteria by protozoa may, in effect, increase the 'dilution rate' of the bacterial population and so increase bacterial growth rate. However, this does not seem to occur in the rumens with only Entodinium or Entodinium + Polyplastron, as the VFA concentrations here were similar to those in the unfaunated sheep, and the proportions of viable bacteria are not increased by the presence of the protozoa (Table I). In sheep 28 (Polyplastron+ Entodinium) the concentrations of VFA tended to decrease at $3 \mathrm{hr}$ after feeding and this correlates with a decrease in bacterial numbers (Fig. I), and with a slight increase in numbers of Polyplastron and Entodinium. This suggests that the bacteria are mainly responsible for VFA formation.

One of us (Y.K.) is indebted to The Agricultural Research Council for a grant to work at the Rowett Research Institute and to The Wellcome Trust for financial help in travelling. The technical assistance of W. Shand, R. Summers and Judith Brand is acknowledged. 


\section{REFERENCES}

Abou Akkada, A. R. \& El Shazly, K. (1964). Effect of absence of ciliate protozoa from the rumen on microbial activity and growth of lambs. Appl. Microbiol. 12, 384.

Abou Akkada, A. R. \& Howard, B. H. (1960). The biochemistry of rumen protozoa. 3. The carbohydrate metabolism of Entodinium. Biochem. J. 76, 445.

Abou Akkada, A. R., Eadie, J. M. \& Howard, B. H. (1963). The biochemistry of rumen protozoa 7. The carbohydrases of Polyplastron multivesiculatum (Dogiel \& Fedorowa). Biochem. J. 89, 268.

Blackburn, T. H. (1965). Protease production by Bacteroides amylophilus, a rumen bacterium. Ph.D. thesis, University of Aberdeen.

Blackburn, T. H. \& Hobson, P. N. (1960). The degradation of protein in the rumen of the sheep and the redistribution of the protein nitrogen after feeding. Brit. J. Nutr. 14, 445.

Bryant, M. P. \& Robinson, I. M. (I96I). An improved non-selective culture medium for ruminal bacteria and its use in determining diurnal variation in numbers of bacteria in the rumen. J. Dairy Sci. 44, 1446.

Bryant, M. P., Robinson, I. M. \& CHU, H. (1959). Observations on the nutrition of Bacteroides succinogenes-a ruminal cellulolytic bacterium. J. Dairy Sci. 42, $183 \mathrm{I}$.

Boyne, A. W., EAdIE, J. M. \& RAITT, K. (I957). The development and testing of a method of counting rumen ciliate protozoa. J. gen. Microbiol. 17, $4 \mathrm{I} 4$.

Christiansen, W. C., Kawashima, R. \& Burroughs, W. (1965). Influence of protozoa upon rumen acid production and liveweight gains in lambs. J. Anim. Sci. 24, 730.

Coleman, G. S. (1964). The metabolism of Escherichia coli and other bacteria by Entodinium caudatum. J. gen. Microbiol. 37, 209.

EADIE, J. M. (1962a). The development of rumen microbial populations in lambs and calves under various conditions of management. J. gen. Microbiol. 29, 563.

EADIE, J. M. (I962 b). Inter-relationships between certain rumen ciliate protozoa. J. gen. Microbiol. 29, 579.

EAdie, J. M. \& Hobson, P. N. (1962). Effect of the presence or absence of rumen ciliate protozoa on the total rumen bacterial count in lambs. Nature, Lond. 193, 503.

El Shazly, K. \& Hungate, R. E. (1965). Fermentation capacity as a measure of net growth of rumen microorganisms. Appl. Microbiol. r3, 62.

GuTIERREZ, J. (1958). Observations on bacterial feeding by the rumen ciliate Isotricha prostoma. J. Protozool. 5, 122.

Gutierrez, J. \& Davis, R. E. (I959). Bacterial ingestion by the rumen ciliates Entodinium and Diplodinium. J. Protozool. 6, 222.

GuTIERREZ, J. \& HuNGATE, R. E. (I957). Inter-relationships between certain bacteria and the rumen ciliate Dasytricha ruminantium. Science, N.Y. 126, 5 I I.

Hobson, P. N. \& ManN, S. O. (I96I). The isolation of glycerol-fermenting and lipolytic bacteria from the rumen of the sheep. J. gen. Microbiol. 25, 227.

Hobson, P. N. \& Summers, R. (1967). Continuous culture of anaerobic bacteria. J. gen. Microbiol. 47, 53.

Hobson, P. N., ManN, S. O. \& SMith, W. (1962). Serological tests of a relationship between rumen selenomonads in vitro and in vivo. J. gen. Microbiol. 29, 265.

Hungate, R. E. (1950). The anaerobic mesophilic cellulolytic bacteria. Bact. Rev. 14, I.

Hungate, R. E. (I966). The Rumen and its Microbes. New York and London: Academic Press.

Luther, R., Trenkle, A. \& Burroughs, W. (I966). Influence of rumen protozoa on volatile acid production and ration digestibility in lambs. J. Anim. Sci. 25, i 16.

Minato, H., Endo, A., Оотомo, Y. \& UEMURA, T. (I966). Ecological treatise on the rumen fermentation. II. J. gen. appl. Microbiol. 12, 53 .

MoIR, R. J. \& Masson, M. J. (1952). An illustrated scheme for the microscopic identification of the rumen microorganisms of sheep. J. Path. Bact. 64, 343.

Purser, D. B. \& MoIr, R. J. (I959). Ruminal flora studies in the sheep. IX. The effect of pH on the ciliate population of the rumen in vivo. Aust. J. Agric. Res. ro, 555. 
288 Y. KURIH ARA, J. M. EADIE, P. N. HOBSON AND S. O. MANN

PURSER, D. B. \& MoIR, R. J. (I966). Dietary effects upon concentrations of protozoa in the rumen. J. Anim. Sci. 25, 668.

WARNER, A. C. I. (1962). Some factors influencing the rumen microbial population. J. gen. Microbiol. 28, 129.

WARNER, A. C. I. (I966). Diurnal changes in the concentrations of micro-organisms in the rumens of sheep fed limited diets once daily. J. gen. Microbiol. 45, 213. 